\title{
Design and Construction of GreenWAVE Energy Converter for Shallow Waters off South Australia
}

\author{
Leigh D. Appleyard \\ ACOR Consultants Pty Ltd., Sydney 2000, Australia
}

\begin{abstract}
Compared with more well-known renewable energy sources, such as wind and solar, the wave energy industry is relatively new. This paper describes the structural design and construction of the oscillating water column "greenWAVE Energy Converter" which was constructed during 2013 and was planned to be deployed in shallow water off the South Australian coast in 2014. Rated initially at $1 \mathrm{MW}$, the greenWAVE unit will be dedicated to electricity production, although an option is available to produce desalinated seawater. The unit base is constructed from reinforced concrete designed to international maritime codes, and the unit will be founded in approximately $10 \sim 15 \mathrm{~m}$ of water. The upper portion of the device extends above sea level, housing the airwave turbine and electrical control systems.
\end{abstract}

Key words: Wave energy, oscillating water column, design wave.

\section{Introduction}

Ocean waves are a huge largely untapped energy resource, and the potential for extracting energy from waves is considerable. Research in this area is driven by the need to meet renewable energy targets, although it has remained relatively immature compared with other renewable technologies.

A recent independent market assessment estimated the potential wave energy economic contribution to the world-wide electricity market to be of the order of $2,000 \mathrm{TWh} /$ annum, which is approximately $12 \%$ of world energy consumption [1]. The International Energy Agency estimates that there is a potential for wave energy conversion to contribute anywhere between $10 \%$ and $50 \%$ of current world yearly electricity demand of about $16,000 \mathrm{TWh}$.

There are various concepts for wave energy conversion. WECs (Wave Energy Converters) are generally categorized by energy conversion mechanism. In general terms, there are presently three

Corresponding author: Leigh D. Appleyard, M.Eng.Sc., M.Env.Eng.Sc., research fields: maritime structures and alternative reinforcement materials for concrete. E-mail: LAppleyard@acor.com.au. kinds of wave energy conversion systems being developed:

(1) channel systems, which funnel waves into reservoirs;

(2) floating systems, which drive hydraulic pumps, and

(3) oscillating water column systems, which utilize wave action to compress air within a geometrically proportioned chamber.

OWC (oscillating water column) devices are known as one of the more efficient ways to capture and convert the wave energy to electricity.

The GEC (greenWAVE Energy Converter) [2] includes a chamber with an opening to the sea below the waterline. As waves approach the device, water is forced into the chamber, applying pressure on the air within the chamber. This air escapes to atmosphere through a turbine. As the water retreats, air is then drawn in through the turbine. A low-pressure Wells turbine is often used in this application as it rotates in the same direction irrespective of the flow direction, removing the need to rectify the airflow. It has been suggested that one of the advantages of this concept is its simplicity and robustness. 
Such robustness needs to be assured in recognition of the severe and variable load regime associated with the in-service location of the GEC. The unit is planned to be located approximately 10 12 km offshore from the South Australian coast in the Great Australian Bight (Fig. 1) [3].

The GEC (described in this paper) comprises a reinforced concrete substructure below sea level and a reinforced concrete superstructure housing the turbine, generator set and electrical control system above sea level, as shown in Fig. 2.

\section{Design Regime}

The GEC is intended for a design service life of 25 years.

Current Australian standards [4] provide only limited design guidance for maritime structures and offshore structures in general. Australian Standard 4997-2005 (AS 4997) [4] is titled "Guidelines for the Design of Maritime Structure", the emphasis being on "guidelines".

Eq. 5.9.2 of AS 4997-2005 defines the design wave for offshore structures as $H_{1}$, being the average of the highest $1 \%$ of all waves for the design storm event.

Simplistically, AS 4997 suggests:

$$
H_{1}=f H_{s}
$$

where, $H_{s}=$ significant wave height = average height of highest $1 / 3$ of waves in any given time interval as estimated by "an expert observer". And, $f=$ coefficient of wave height.

More relevantly, AS 4997 suggests that "the design wave conditions may be determined by more specific modelling”.

\subsection{Selection of Design Wave}

Wave data was available from a variety of sources, which - when considered together-resulted in a fairly broad scatter with $H_{s}$ varying between $6.5 \mathrm{~m}$ and $10.0 \mathrm{~m}$, based on the modified Goda relationship [5].

This broad scatter of $H_{s}$ values was of limited value, given the range of design outcomes for concrete section sizes and reinforcement density, and, of course, the resulting construction cost.

\subsection{Model Tank Testing}

As recommended in AS 4997, a series of model trials were conducted at the Australian Maritime College facilities in Launceston, Tasmania, identified as LMC (Launceston Maritime College).

The final report recommended that design should proceed on the basis of a design wave:

$$
H_{\max }=9.25 \mathrm{~m}, T_{s}=12 \mathrm{~s}
$$

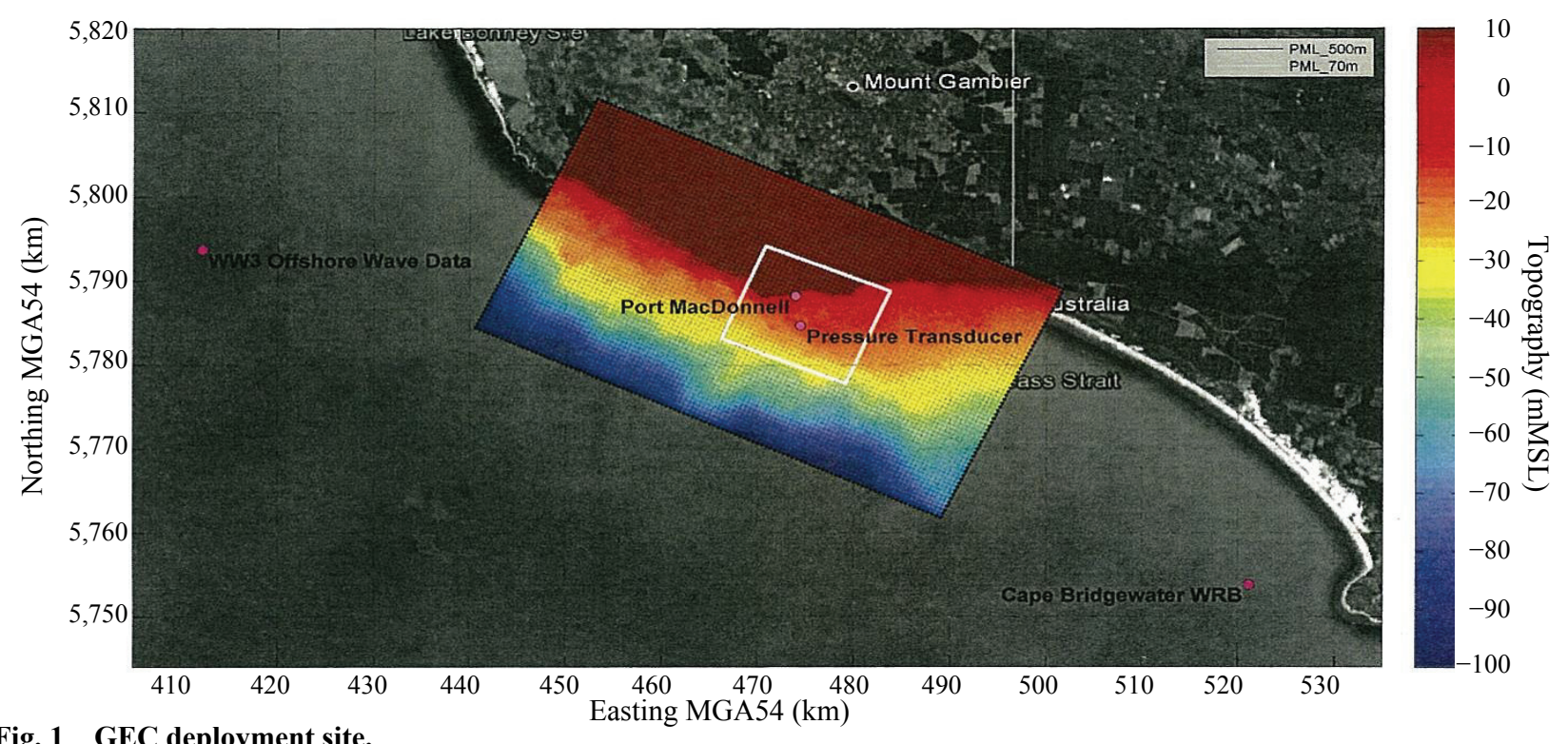

Fig. 1 GEC deployment site. 


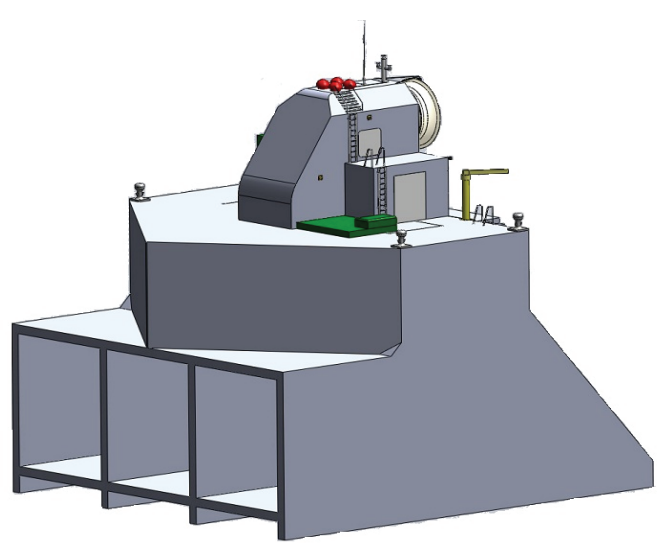

(a)

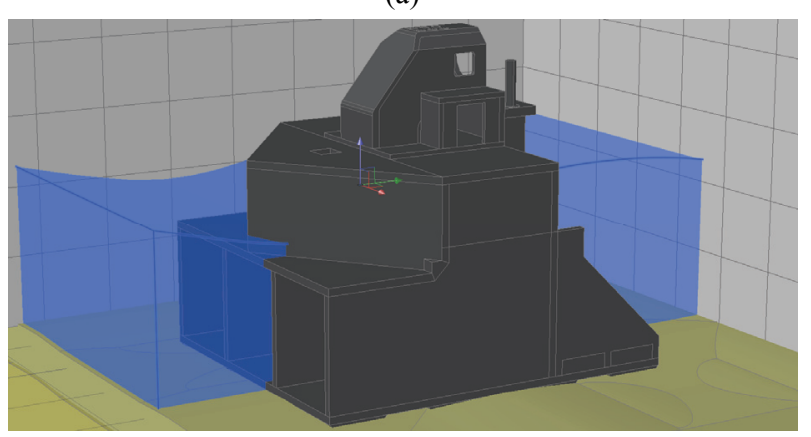

(b)

Fig. 2 GEC structure: (a) isometric view; (b) in relation to water line.

However, the largest wave which was able to be generated in the tank testing was the equivalent of
$6.0 \mathrm{~m}$. Therefore, any extrapolation of design loads from $6.0 \mathrm{~m}$ to $9.5 \mathrm{~m}$ would require further validation.

Whilst considered to be of some value, the model testing was in fact limited in direct relevance to the design regime for the GEC.

\section{Literature Review}

An extensive literature review was conducted with valuable guidance found to be available from well-known researchers including Cuomo et al. [6] and Xia et al. [7].

Fig. 3 plots wave height and total horizontal force for various wave heights and periods resulting from the literature survey and also the LMC results.

The significance of the quasi-static curve (shown at top) was of considerable concern since-at first glance - it appeared to provide a "better line of fit" with the model test data. However, adoption of design loads based on the quasi-static correlation would have rendered the project totally uneconomic.

All of the available data were re-plotted and a correlation band was recognized, as reproduced in Fig. 4.

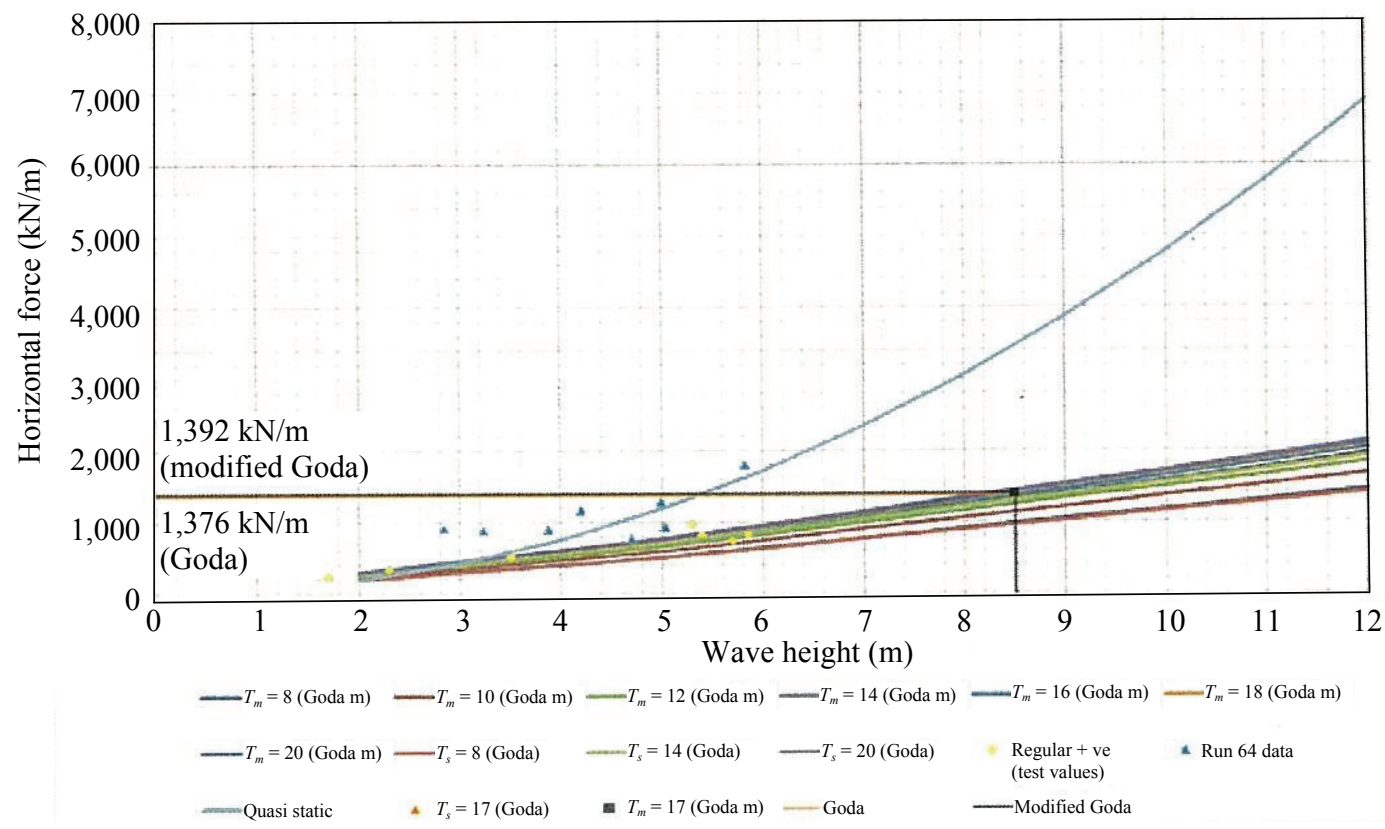

Fig. 3 Wave height and total horizontal force for various wave heights and periods. 


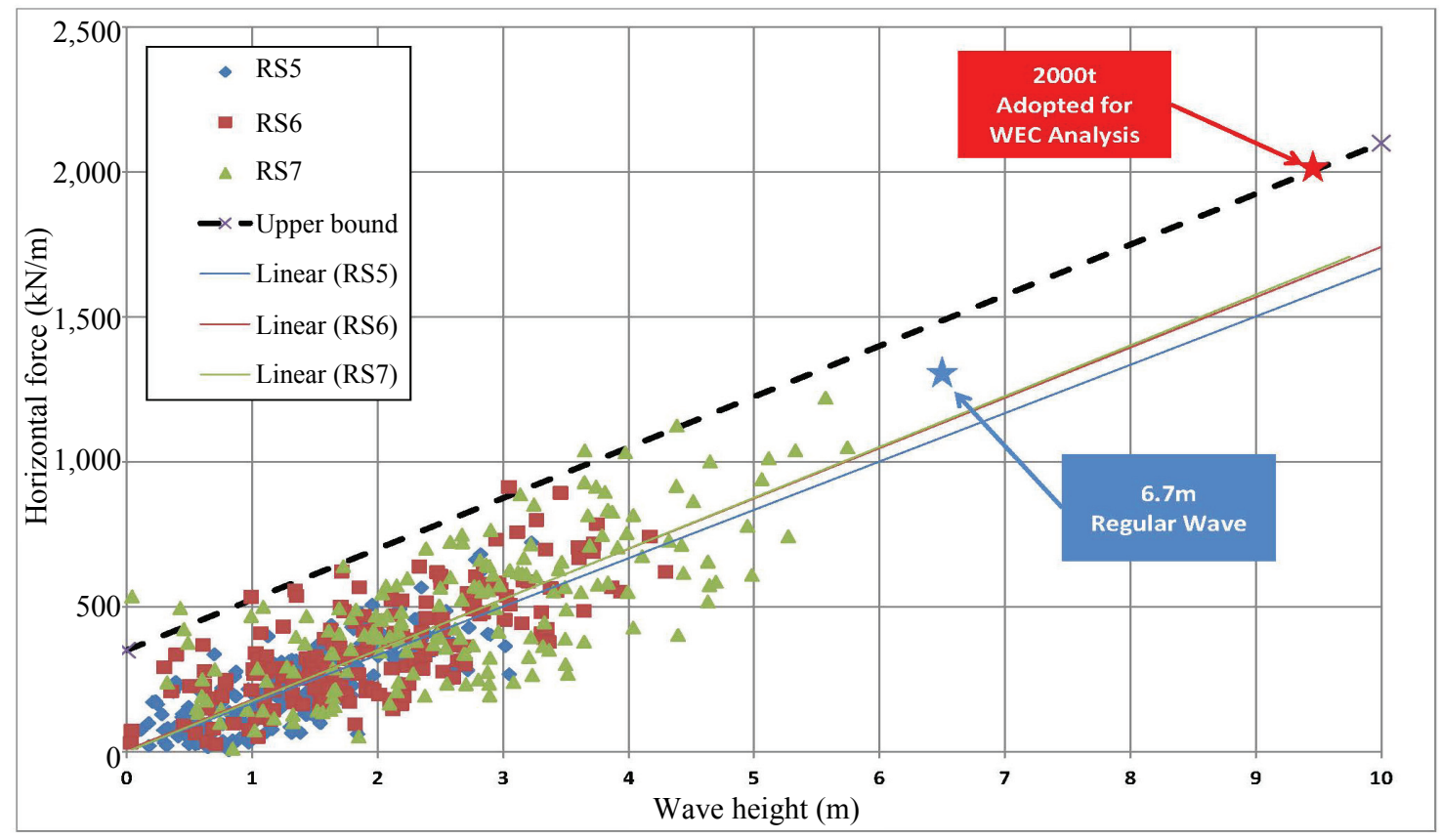

Fig. 4 Data correlation band.

\section{Structural Design Regime}

As with all maritime structures, durability (commensurate with a 25-year design life) was the primary focus for the structural design of the GEC.

\subsection{Crack Control}

AS 4997-2005 provides for crack control in maritime structures being achieved by limiting tensile stresses in carbon steel reinforcement to a value between $150 \mathrm{MPa}$ and $185 \mathrm{MPa}$, depending on bar diameter.

\subsection{Cover to Reinforcement}

It was decided that it was appropriate to adopt two exposure classifications for the GEC based on AS 4997-2005.

Classification B2 was adopted for the lower submerged portion of the structure, and Classification C2 for the upper superstructure portion.

In addition, galvanized reinforcement was specified for all areas of maximum moment transfer and other critical locations throughout the structure. The balance of the reinforcement was non-galvanized, with all reinforcement stress limits as noted previously.

\subsection{Fatigue}

AS 4997-2005 provides only limited guidance with regard to fatigue, noting: "The magnitude of the repeated loadings when designing such structures, or elements of structures, for fatigue performance should be determined from in-service cyclic actions."

A value of $10^{6}$ cycles per annum is suggested for wave periods of 2 4 $\mathrm{s}$.

This value is generally in line with other literature including a valuable paper by Waagaard [8], which states: "No endurance limit is found up to $10^{7}$ cycles on testing of plain concrete."

Further, it is accepted in the offshore gravity structure area that the cycling frequency of such structures is low, generally in the region of $0.05 \mathrm{~Hz}$ to $0.30 \mathrm{~Hz}$. Accumulated experimental data indicate that frequencies up to $10.0 \mathrm{~Hz}$ do not affect fatigue strength of concrete (plain or reinforced).

\subsection{Buoyancy and Towing Actions}

The GEC was constructed at the common user facility at Techport, north of Adelaide, South Australia. 


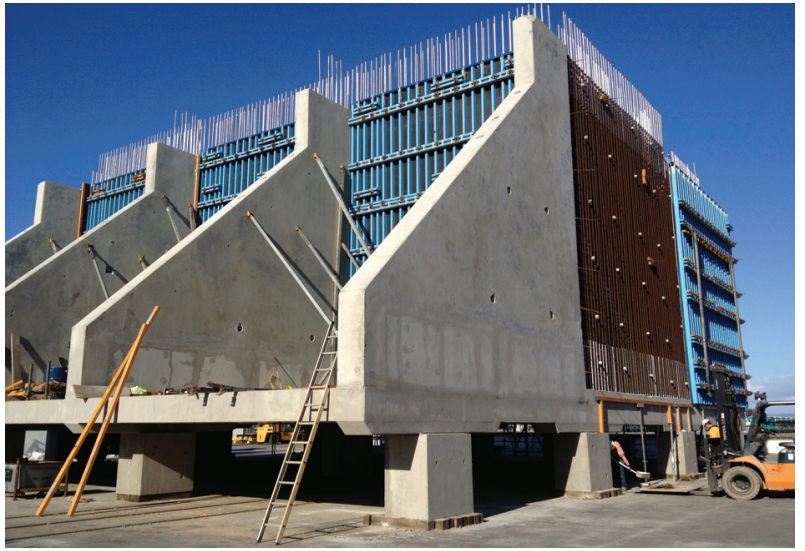

(a)

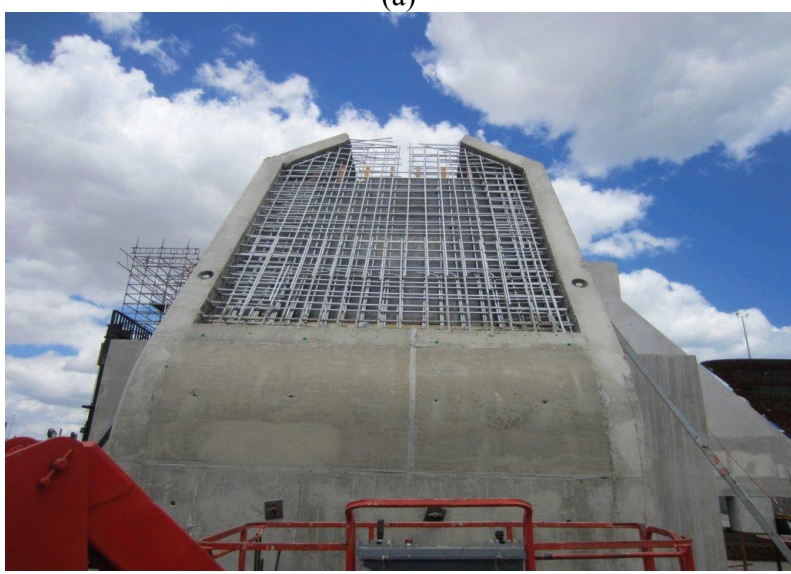

(b)

Fig. 5 GEC construction in September 2013 (photographed by author on September 10, 2013).

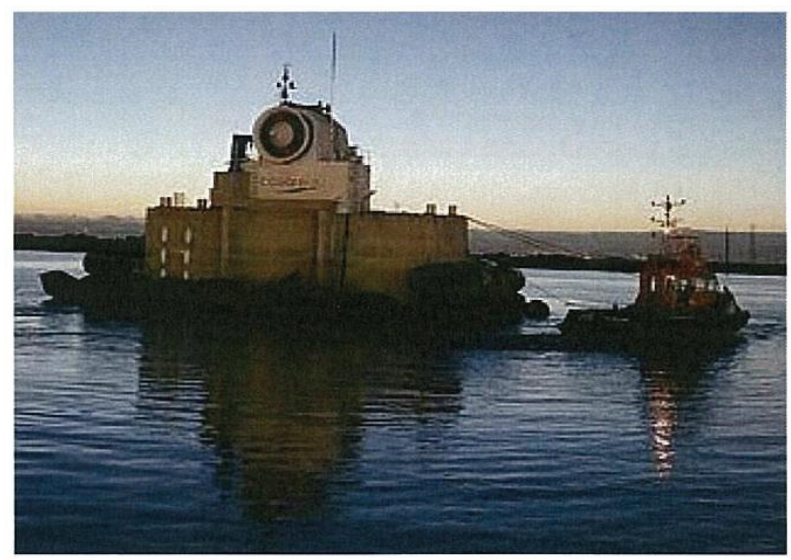

Fig. 6 Under tow in March 2014.

Photographs of the GEC, nearing completion in September 2013, are shown in Fig. 5.

Buoyancy for the unit during deployment from Techport to Port MacDonnell (approximately $400 \mathrm{~km}$ ) was to be provided by: (a) fitting a removable steel bulkhead across the major openings at the front of the structure;

(b) fitting a number of air filled buoyancy bags around the perimeter of the unit in locations determined by the naval architect for the project.

The planned towing speed for deployment of the GEC was 4 knots.

Cast-in items were provided throughout the concrete substructure and superstructure to accommodate the buoyancy and towing loads.

\subsection{In-situ Stability}

Two main failure modes for the in-situ GEC were considered, based on the ultimate limit state design wave discussed at Sections 2 and 3 above.

\subsubsection{Overturning}

Considering the total submerged mass of the structure as the only resistance against overturning, a safety factor of 2.3 was adopted.

\subsubsection{Sliding}

Extensive iterations were conducted to determine a "comfortable" value for sliding resistance.

It was acknowledged that small $(0 \sim 0.5 \mathrm{~m})$ horizontal movements by the GEC could be accommodated without any impact on the power generating efficiency of the unit.

This enabled relaxation of sliding factors of safety below those which would be required for assurance of fixity in location. Detailed dynamic analysis suggested that with a friction coefficient as low as 0.5 , the GEC would undergo a horizontal translation of less than $100 \mathrm{~mm}$ for a wave load of $25,000 \mathrm{kN}$ (1.25 times the design wave load) [9].

\section{Current Status of GEC}

Construction of the GEC was completed in early 2014 and the unit was launched in early March 2014, as shown in Fig. 6.

Shortly after towing the unit was commenced, a problem was detected with the buoyancy air bags, resulting in an unstable state and the unit was towed to 
shallow water in south of Adelaide for repairs to be made prior to final deployment.

\section{Main Findings}

Adoption of land based construction for the GEC compared with in situ construction offshore revealed considerable cost benefits even after towing and installation costs were factored in. Land based construction also afforded better opportunities for quality assurance of what is essentially a concrete maritime structure.

Rated initially at $1 \mathrm{MW}$, the GEC will be capable of incremental modular additions to provide greater in-service capacities.

\section{Acknowledgments}

The permission of Oceanlinx Ltd. for preparation of this paper is gratefully acknowledged.

\section{References}

[1] IEA (International Energy Agency) Fact Sheet. 2009.
Renewables in Global Energy Supply. Paris: IEA.

[2] Oceanlinx Ltd. 2013. Information Brochure, October 25. Sydney: Oceanlinx Ltd.

[3] Cardno Pty Ltd. 2012. Design Report. Sydney: Cardno Pty Ltd.

[4] Standards Australia. 2009. "AS 4997-2005." In Guidelines for the Design of Maritime Structures. Sydney: Standards Australia

[5] Goda, Y. 1974. "New Wave Pressure Formulae for Composite Breakwaters." In Proceedings of International Conference on Coastal Engineering, Vol. 3, No. 14, 1702-20.

[6] Cuomo, G., Allsop, W., Bruce, T., and Pearson, J. 2010 "Breaking Wave Loads at Vertical Seawalls and Breakwaters.” Coastal Engineering 57 (4): 424-39.

[7] Xia, J., and Krokstad, J. R. 2001. "Wave Forces on a Body in Confined Waters." Presented at 14th Australasian Fluid Mechanics Conference, Adelaide, Australia.

[8] Waagaard, K. 1977. "Fatigue of Offshore Concrete Structures-Design and Experimental Investigations." Presented at Offshore Technology Conference, Houston, Texas, USA.

[9] Hong, S. Y., Suh, K. D., and Kweon, H. M. 2004. "Calculation of Expected Sliding Distance of Breakwater Caisson Considering Variability in Wave Direction." Coastal Engineering Journal 46: 119-40. 